\title{
A family with dynamin 2-related centronuclear myopathy without ocular involvement
}

\author{
Jin-Sung Park', Dae-Seong Kim², and Jin-Hong Shin ${ }^{2, *}$ \\ ${ }^{1}$ Department of Neurology, Kyungpook National University Hosipital, Kyungpook National University School of Medicine, Daegu, Korea \\ ${ }^{2}$ Department of Neurology, Pusan National University Yangsan Hospital, Yangsan, Korea
}

Centronuclear myopathy (CNM) is a rare congenital myopathy that is pathologically characterized by the centrally located nuclei in most of the muscle fibers. On clinical examination, dynamin 2 (DNM2)-related CNM typically shows distal dominant muscle atrophy, ptosis, ophthalmoplegia, and contracture. The reported cases of CNM in Caucasian studies show a high prevalence rate of early-onset ptosis and ophthalmoplegia and correlated with the severity of the disease. However, Asian reports show a low prevalence and late-onset ocular symptoms in DNM2-related CNM patients. p.R465W is one of the most commonly found mutations in Western countries, and all the cases showed ocular symptoms. The proband and his daughter had no ocular symptoms despite harboring the same p.R465W mutation. This family makes us speculate that ocular symptoms in DNM2-related CNM are influenced by ethnic background. In addition, this is the first familial case of DNM2related CNM in Korea.

Key words: Centronuclear myopathy, Dynamin II, Ophthalmoplegia.

\section{Introduction}

Centronuclear myopathy (CNM) is a rare congenital myopathy. Its name originates from the peculiar pathological finding of most muscle fibers having one or more myonuclei at the center [1]. Among the various types of CNM, dynamin 2 (DNM2)related CNM assumes an autosomal dominant trait (OMIM 602378). However, the prevalence of CNM is unknown because of its rarity. Patients show slowly progressive limb weakness and atrophy that begin in childhood or early adolescence and a normal life span. Most reported cases show distal muscle weakness with high frequency of ocular symptoms that manifest as ophthalmoplegia or ptosis. Four genes have been reported to cause CNM, namely myotobularin (MTM1), DNM2, ryanodine 1 (RYR1), and amphiphysin 2 (BIN1) [2]. We present the first reported familial case of DNM2-related CNM among Koreans that showed no ocular symptoms, extending the phenotypic variability of the DNM2-related CNM.

\section{Case}

A 48-year-old man presented with progressive weakness that started in the first decade of his life. He had difficulty climbing stairs since the third decade of his life. The initial neurological examination of the patient revealed a slender myopathic face with temporal muscle atrophy, without ptosis or ophthalmoplegia (Fig. 1A). Motor power examination revealed that the motor powers in his proximal and distal muscles were of

Received: 5 December 2015, Revised: 18 January 2016, Accepted: 26 January 2016, Published: 30 June 2016

${ }^{*}$ Corresponding author: Jin-Hong Shin, M.D., Ph.D.

Department of Neurology, Pusan National University Yangsan Hospital, 20 Geumo-ro, Mulgeum-eup, Yangsan 50612, Korea.

Tel: +82-55-360-2450, Fax: +82-55-360-2152, E-mail: shinzh@gmail.com

Conflict of interest: The authors declare that they do not have any conflicts of interest.

(ac) This is an open-access article distributed under the terms of the Creative Commons Attribution Non-Commercial License (http://creativecommons.org/licenses/by-nc/4.0/) which permits unrestricted non-commercial use, distribution, and reproduction in any medium, provided the original work is properly cited.

(c) Copyright 2016 by the Korean Society of Medical Genetics 
A

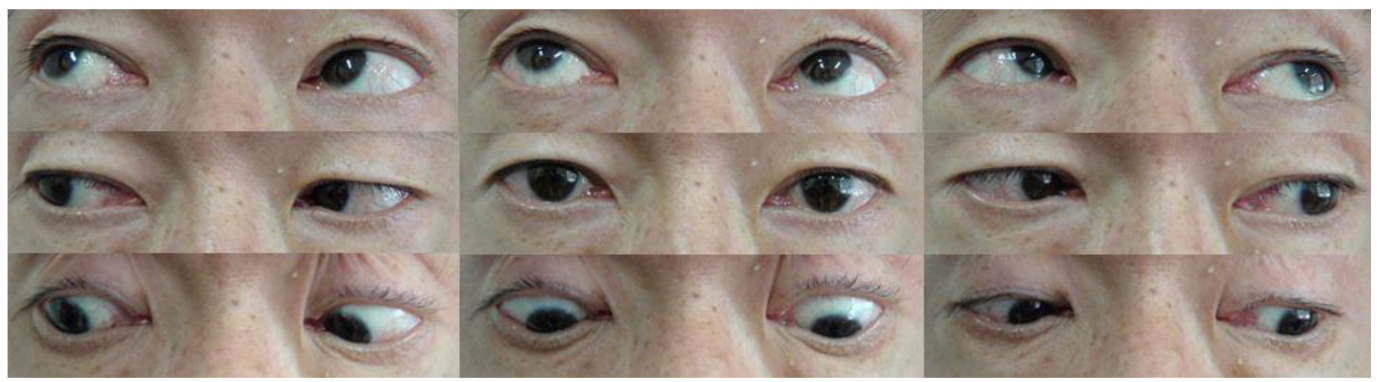

B

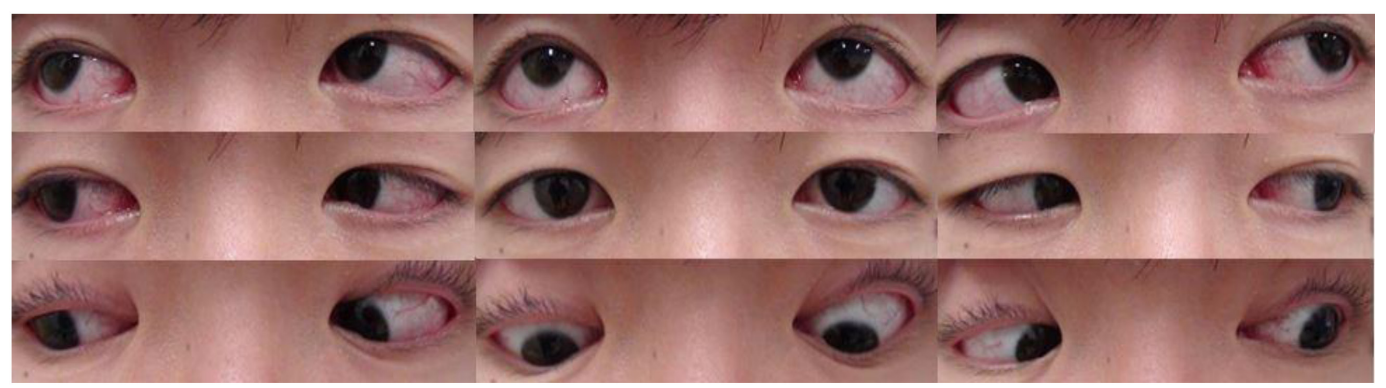

Fig. 1. The 9-gaze photograph of the proband (A) and his daughter (B). They show no clinical evidence of ptosis and ophthalmoplegia, that are known to be characteristic features of dynamin 2 (DNM2)-related centronuclear myopathy.

A
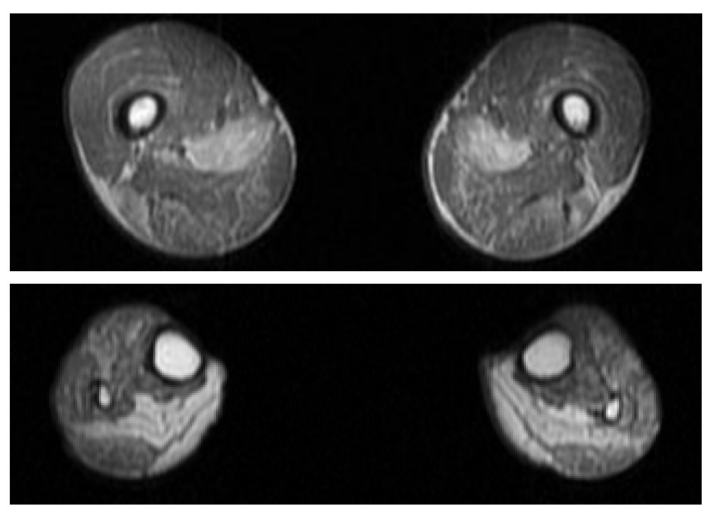

B

C CAC T TACATC TGGGAACG G G A G G
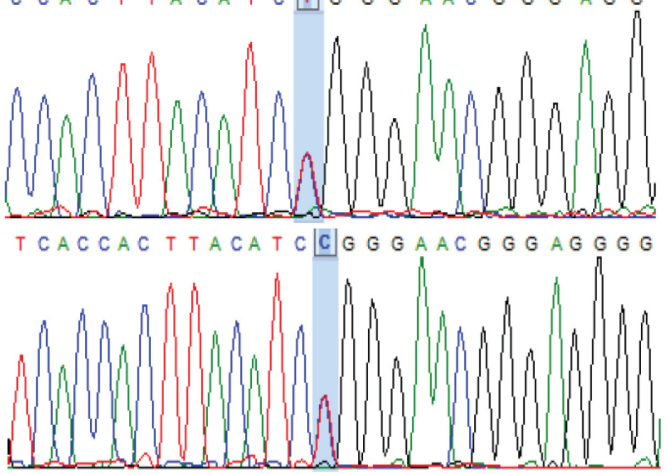

Fig. 2. The lower extremity of the proband and p.R465W mutation confirmed by Sanger sequencing. Magnetic resonance images showing a selective fatty change in the medial gastrocnemius and soleus muscles $(A)$, which is a characteristic feature in dynamin 2-related centronuclear myopathy (B).

Medical Research Council (MRC) grade 4/5 and 2/5, respectively. His daughter also had an elongated face, without ptosis or ophthalmoplegia (Fig. 1B). She showed a mildly disabled tiptoe gait. She had a motor weakness of MRC grade $4+/ 5$ with finger fanning and MRC grade 4+/5 at the ankles.

The laboratory findings for the proband were unremarkable, except for the borderline elevation of the creatine kinase level (187 U/L). A nerve conduction study revealed a mildly reduced compound motor action potential in the median, ulnar, and peroneal nerves, without significant slowing in the nerve conduction velocities. A needle electromyographic study revealed active denervation potentials with positive sharp waves and fibrillation potentials with small amplitude polyphasic motor unit potentials and early recruitment pattern in the left biceps and tibialis anterior muscles. The pulmonary function of the patient was mildly reduced along with his forced vital capacity (73\%) and 1-second forced expiratory volume (91\%). He could walk $436.2 \mathrm{~m}$ in the 6 -minute walk test. The results 
of the transthoracic echocardiography and 24-hour Holter monitoring were unremarkable. Muscle magnetic resonance imaging (MRI) revealed an extensive fatty infiltration in the posterior thigh and distal leg muscles, with severe involvement in the bilateral adductor magnus, medial gastrocnemius, and soleus muscles (Fig. 2A). Muscle biopsy was performed for the patient's left biceps muscle and revealed numerous central nuclei in most of the muscle fibers, with disrupted myofibril and type 1 fiber hypotrophy, which were compatible with a typical CNM (Fig. 3). In the genetic analysis for DNM2, the Western prototypic pathogenic mutation p.R465W was detected heterozygously both in the genome of the proband and his daughter (Fig. 2B).

\section{Discussion}

DNM2-related CNM presents with a mild phenotype with slowly progressive muscle weakness and high prevalence of ptosis and/or ophthalmoplegia. Deep tendon reflexes are abolished in most cases, and Achilles tendon contractures are frequent. Heart and respiratory muscles are not involved, which explains the normal life span in patients. DNM2 mutations can also cause Charcot-Marie-Tooth disease, with both conditions sharing the features of prominent distal leg atrophy and weakness [3].
DNM2 plays an important role as a mechanochemical enzyme in endosome formation and membrane trafficking from plasma membrane and Golgi apparatus. Five functional domains have been identified as follows: GTPase domain, middle domain (MID), pleckstrin homology (PH) domain, GTPase effector domain (GED) and proline-rich domain. Mutations in the MID domain are known to be associated with mild adult-onset DNM, as in the present case. Mutations in the $\mathrm{PH}$ domain are known to be associated with severe neonatal CNM. All the mutations reported to date are in the MID, GED, and PH domains, while most patients harbor MID mutations [4].

The reported Caucasian cases had a high incidence of ocular symptoms such as ptosis and ophthalmoplegia, which are less frequently reported among Asians. Bitoun et al. [5] reported a p.R465W DNM2 mutation in 26 Caucasian families of various racial origins that presented with marked interfamilial and intrafamilial variabilities. It is the most common DNM2 mutation reported in Western countries. Of 32 patients reported to have DNM2-related CNM with p.R465W mutation, 30 patients (94\%) had either ophthalmoplegia or ptosis [5-8]. In Asia, the most common mutation reported among DNM2related CNM patients is p.R369W [9-11]. Asian reports describe much lower frequencies of ocular symptoms, with only 7 of 19 patients having either ptosis or ophthalmoplegia. The difference in clinical features of DNM2-related CNM between Asians and

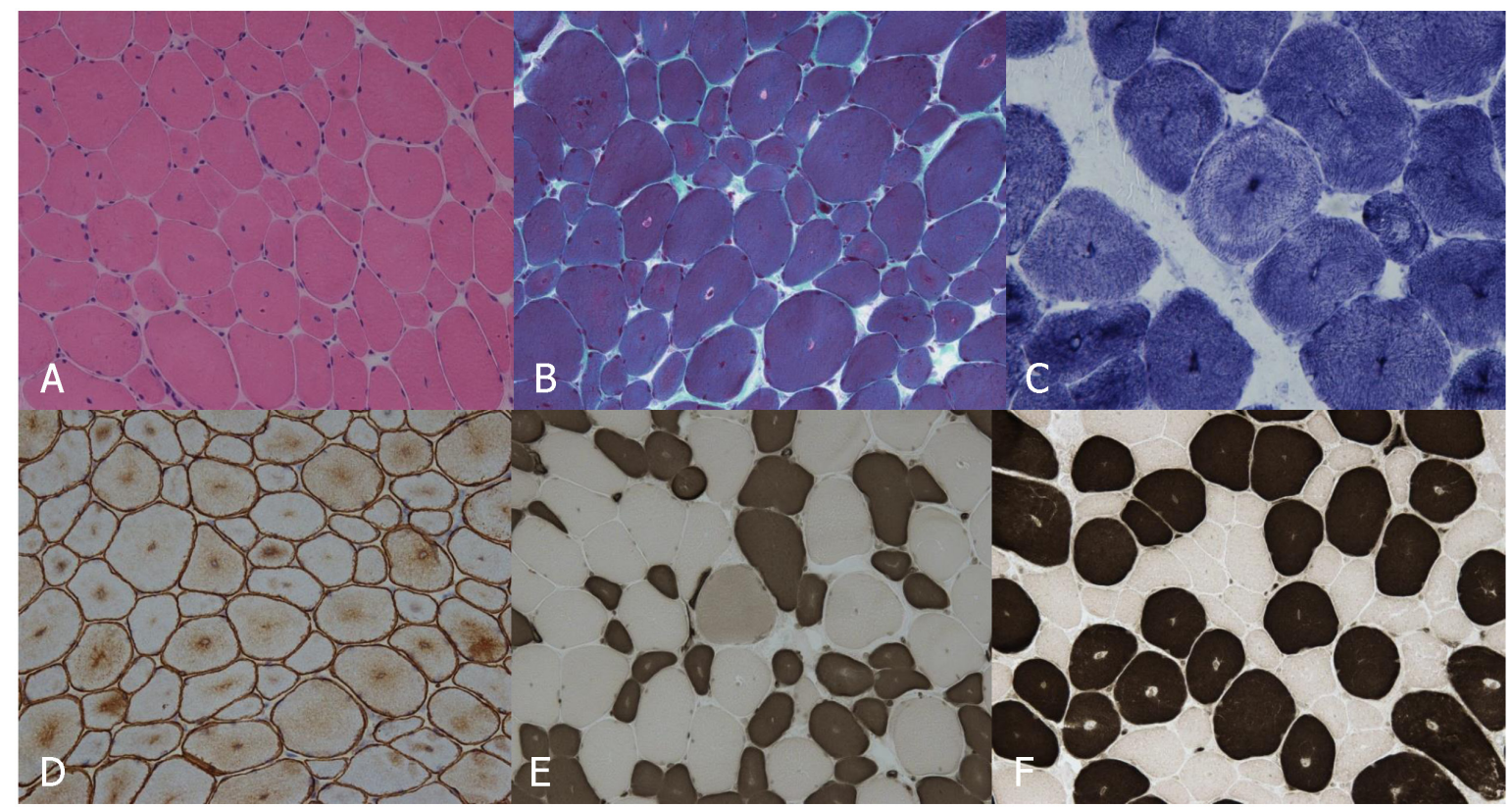

Fig. 3. The muscle biopsy result of the proband. Numerous fibers with central nuclei and radial sarcoplasmic strands can be observed. Selective type 1 fiber hypotrophy can also be observed (A-D), compatible with centronuclear myopathy (E and F). (A) Hematoxylin-eosin stain, $\times 200$; (B) modified Gomori trichrome stain, $\times 200$; (C) nicotinamide adenine dinucleotide-tetrazolium reductase stain, $\times 400$; (D) dystrophin stain, $\times 200$; (E) ATPase 4.6 stain, $\times 200$; and (F) ATPase 10.6 stain, $\times 200$. 
Caucasians warrants speculation whether the difference lies in the specific DNM2 mutation or the broader genetic influence. The family we describe is definitely of Asian lineage without ptosis or ophthalmoplegia, yet harbors the western prototype mutation p.R465W. It is an excellent opportunity to directly compare the identical mutation site between the 2 ethnicities. Hence, our report suggests that ethnic genetic difference has a larger role in influencing the occurrence of ocular signs in DNM2-related CNM than the specific mutation site.

The need to differentiate DNM2-related CNM from RYR1 or BIN1 mutations by muscle MRI is being addressed in recent literatures. DNM-related CNM usually affects the distal muscles in the early stage of the disease. The distal posterior compartment muscles are affected earlier than the proximal muscles, and the effect on the medial gastrocnemius and soleus muscles are generally greater than that on the tibialis anterior muscles [12]. Our patient also showed a highly selective involvement of the gastrocnemius and soleus muscles with relative sparing of the proximal muscles. Therefore, recognition of the specific imaging pattern can be useful in distinguishing the causal mutation in CNM patients.

This is the first Korean familial case of DNM2-related CNM with a western prototype mutation of $p . R 465 \mathrm{~W}$. The family had no characteristic features of ptosis and ophthalmoplegia, which are highly observed in DNM2-related CNM, especially in patients with p.R465W mutation. Our case broadens the phenotypic variability in DNM2-related CNM with an ethnicity difference. Thus, we must consider CNM even in patients who do not present with typical ocular involvement especially in Asian ethnicities.

\section{Acknowledgements}

This study was supported by clinical research grant 2015 of Pusan National University Yangsan Hospital.

\section{References}

1. Jungbluth $H$, Wallgren-Pettersson $C_{\text {, Laporte J. Centronuclear }}$ (myotubular) myopathy. Orphanet J Rare Dis 2008;3:26.

2. Jungbluth $H$, Gautel M. Pathogenic mechanisms in centronuclear myopathies. Front Aging Neurosci 2014;6:339.

3. Echaniz-Laguna A, Nicot AS, Carré S, Franques J, Tranchant $C_{1}$ Dondaine $N$, et al. Subtle central and peripheral nervous system abnormalities in a family with centronuclear myopathy and a novel dynamin 2 gene mutation. Neuromuscul Disord 2007;17:955-9.

4. Böhm J, Biancalana $V$, Dechene ET, Bitoun M, Pierson CR, Schaefer $E_{\text {, et }}$ al. Mutation spectrum in the large GTPase dynamin 2, and genotype-phenotype correlation in autosomal dominant centronuclear myopathy. Hum Mutat 2012;33:949-59.

5. Bitoun $M$, Maugenre $S$, Jeannet $P Y$, Lacène $E$, Ferrer $X$, Laforêt $P$, et al. Mutations in dynamin 2 cause dominant centronuclear myopathy. Nat Genet 2005;37:1207-9.

6. Catteruccia M, Fattori F, Codemo V, Ruggiero L, Maggi L, Tasca G, et al. Centronuclear myopathy related to dynamin 2 mutations: clinical, morphological, muscle imaging and genetic features of an Italian cohort. Neuromuscul Disord 2013;23:229-38.

7. Susman RD, Quijano-Roy S, Yang N, Webster R, Clarke NF, Dowling $J$, et al. Expanding the clinical, pathological and MRI phenotype of DNM2-related centronuclear myopathy. Neuromuscul Disord 2010;20:229-37.

8. Hanisch F, Müller T, Dietz A, Bitoun M, Kress W, Weis J, et al. Phenotype variability and histopathological findings in centronuclear myopathy due to DNM2 mutations. J Neurol 2011;258:1085-90.

9. Chen T, Pu C, Wang Q, Liu J, Mao Y, Shi O. Clinical, pathological, and genetic features of dynamin-2-related centronuclear myopathy in China. Neurol Sci 2015;36:735-41.

10. Mori-Yoshimura M, Okuma A, Oya Y, Fujimura-Kiyono C, Nakajima $H$, Matsuura $K$, et al. Clinicopathological features of centronuclear myopathy in Japanese populations harboring mutations in dynamin 2. Clin Neurol Neurosurg 2012;114:678-83.

11. Park YE, Choi YC, Bae JS, Lee CH, Kim HS, Shin JH, et al. Clinical and pathological features of Korean patients with DNM2-related centronuclear myopathy. J Clin Neurol 2014;10:24-31.

12. Fischer $D$, Herasse $M$, Bitoun $M$, Barragán-Campos HM, Chiras J, Laforêt $P$, et al. Characterization of the muscle involvement in dynamin 2-related centronuclear myopathy. Brain 2006;129:1463-9. 